\title{
Longer Length of First Stay in Intermittent Residential Programmes Is Associated with Larger Weight Loss at 1 and 2 Years
}

\author{
Catia Martins $^{a, b} \quad$ Magnus Strommen $^{b, c} \quad$ Bård Kulseng ${ }^{a, b}$ \\ a Obesity Research Group, Department of Cancer Research and Molecular Medicine, \\ Faculty of Medicine, Norwegian University of Science and Technology, ${ }^{b}$ Centre for Obesity, \\ Department of Surgery, St. Olavs Hospital, ' Department of Neuroscience, Faculty of \\ Medicine, Norwegian University of Science and Technology, Trondheim, Norway
}

\section{Key Words}

Cardiovascular fitness $\cdot$ Morbid obesity $\cdot$ Residential programs $\cdot$ Weight loss

\begin{abstract}
Objective: To determine if length of first stay impacts on weight loss and cardiovascular fitness, at 1 and 2 years in severely obese patients enrolled in intermittent residential programs. Methods: In a retrospective follow-up study, we assessed weight loss and changes in cardiovascular fitness $\left(\mathrm{VO}_{2}\right.$ peak) at 1 and 2 years in 179 severely obese adults who participated in two intermittent residential programmes. Both programmes consisted of five stays at the Røros Rehabilitation Centre over a 2-year period, but programme A consisted of a much longer first stay compared with programme B (8 vs. 2 weeks). Results: Of 179 participants (BMI $\left.44 \pm 6 \mathrm{~kg} / \mathrm{m}^{2}\right), 162$ completed 1-year and 117 2-year evaluation. Programme A led to significantly larger weight reduction $(-20.7 \pm 10.8$ vs. $-13.5 \pm 8.1 \mathrm{~kg}$ and $-16.0 \pm 12.7$ vs. $-7.9 \pm 11.2$ $\mathrm{kg}, \mathrm{p}<0.0001)$ and improvement in $\mathrm{VO}_{2}$ peak $(7.8 \mathrm{vs} .3 .6 \mathrm{ml} / \mathrm{kg} / \mathrm{min}(\mathrm{p}<0.0001)$ and $5.6 \mathrm{vs}$. $2.5 \mathrm{ml} / \mathrm{kg} / \mathrm{min}(\mathrm{p}<0.01))$ at both 1 and 2 years, compared with programme B. Intention-totreat analysis showed similar results. Conclusion: A residential intermittent programme with a longer initial stay is associated with better weight loss and improvement in cardiovascular fitness at both 1 and 2 years. A longer follow-up is needed to clearly establish the sustainability of these programmes.

Copyright (c) 2013 S. Karger GmbH, Freiburg
\end{abstract}


Martins et al.: Longer Length of First Stay in Intermittent Residential Programmes Is Associated with Larger Weight Loss at 1 and 2 Years

\section{Introduction}

Over the last decades obesity has taken on epidemic proportions [1]. Obesity increases all-cause mortality and is an independent risk factor for type- 2 diabetes, cardiovascular disease (CVD) and hypertension, making it one of the major public health problems in developing countries [1,2]. Severe obesity, defined as a BMI $\geq 40 \mathrm{~kg} / \mathrm{m}^{2}$, is associated with a significantly higher prevalence of comorbidities [2] and rates of premature mortality twice as those seen in less severe degrees of obesity [3]. The associated socio-economic costs are extremely high and likely to increase [4].

Life-style interventions involving diet, exercise and behaviour modification are still the cornerstone in obesity treatment. Although conservative treatments of obesity can result in short-term weight loss of approximately $10 \%$ body weight, this is usually not sustained in the long term [5]. This has led some to consider bariatric surgery as the only sustainable treatment for morbid obesity [6]. However, not all patients with morbid obesity want bariatric surgery [7], those who want are not always eligible, and less than $1 \%$ of those are treated annually [8]. Moreover, it is important to highlight that even small weight losses (between 5 and $10 \%$ of initial body weight) can have large health benefits if sustained in the long term [9]. A weight loss of only 3-4 kg sustained for 3-4 years has been shown to reduce the development of type 2 diabetes up to $58 \%$ in obese individuals [10]. Therefore, nonsurgical alternatives for severe obesity, which facilitate long-term weight loss maintenance, need to be developed.

The concept of weight loss camps or residential programmes for severely obese adult patients is relatively new, and few data is available, particularly in the long term. Short-term results are usually good, with an average $7 \%$ weight loss being reported after $3-4$ weeks [11, 12 ] and $15 \%$ after 21 weeks [13] of participation in residential weight loss programmes consisting of diet, physical activity and behavioural modification in patients with severe obesity. These changes have been shown to be maintained at 1 year [12], to be of small clinical significance at follow-ups between 2 and 4 years [13] and to disappear almost completely at 5 years [14]. However, all previous studies consisted of only one unique stay at a residential facility and did not involve any additional contact between patients and 'health providers' in order to reinforce the life-style modifications and keep the patients motivated to long-term changes.

We have recently shown that residential intermittent programmes for weight loss involving several stays over time lead to clinical significant weight loss and improvements in risk factors and comorbidities resolution at 1 year similar to those observed after bariatric surgery, despite a much lower weight reduction (40 \pm 14 vs. $22 \pm 13 \mathrm{~kg}$ ) [15].

The present study aims to determine if length of the first stay impacts on weight loss and cardiovascular fitness at 1 and 2 years in severely obese patients enrolled in an intermittent residential programme.

\section{Material and Methods}

\section{Participants}

179 participants (117 women and $62 \mathrm{men}$ ) were included in this analysis. The inclusion criteria were an age between 18 and 60 years and a BMI $>40 \mathrm{~kg} / \mathrm{m}^{2}$ (or BMI $>35 \mathrm{~kg} / \mathrm{m}^{2}$ with comorbidities). The exclusion criteria included pregnancy, enrolment in another obesity treatment, previous bariatric surgery, drug or alcohol abuse and physical or mental impairment that interfere with the ability to comply to treatment. This study was conducted according to the guidelines laid down in the Declaration of Helsinki and was approved by the regional Ethics Committee (Central Norway, Trondheim, Norway). Written informed consent was obtained from all participants before enrolling in the study. 
Martins et al.: Longer Length of First Stay in Intermittent Residential Programmes Is Associated with Larger Weight Loss at 1 and 2 Years

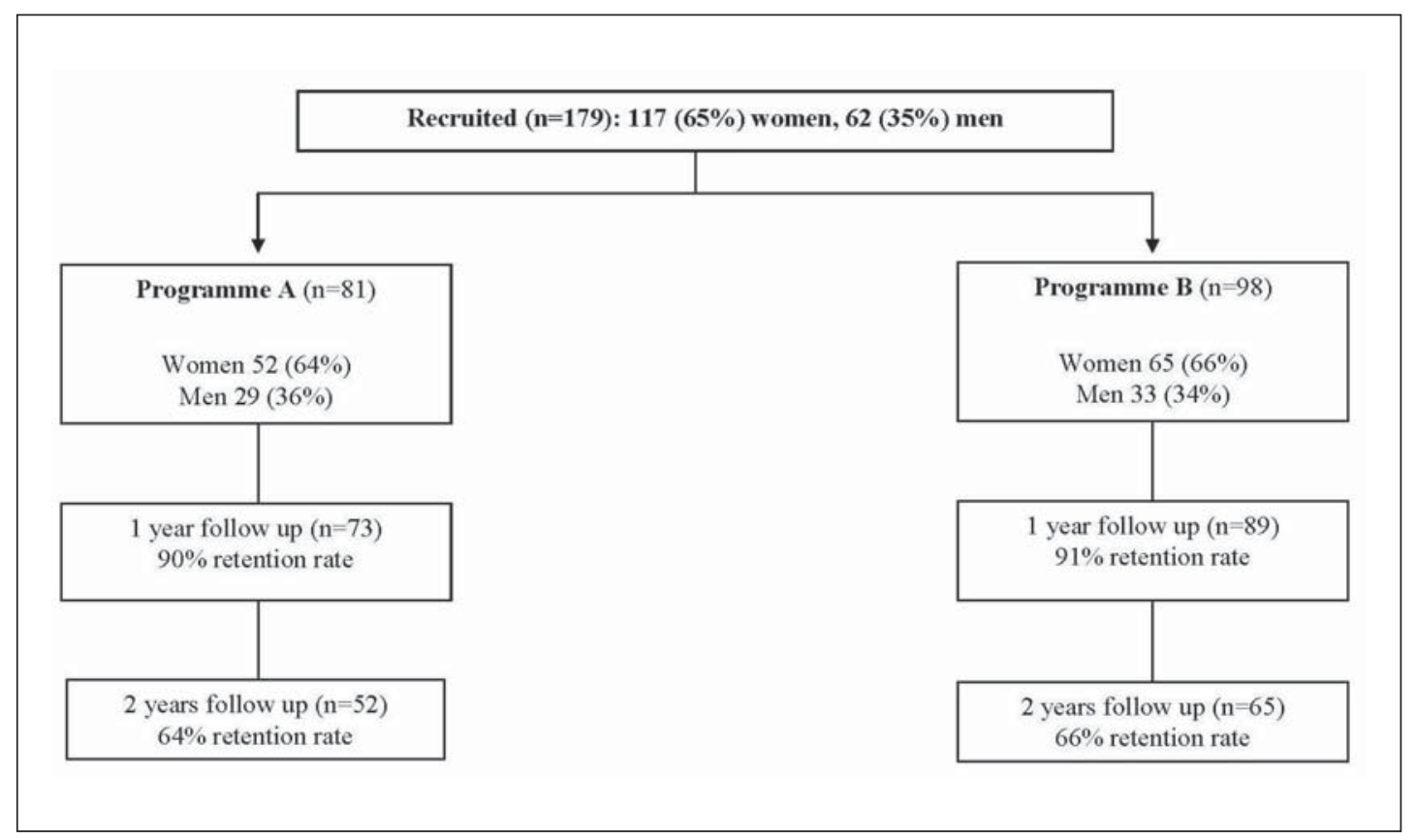

Fig. 1. Participant flow diagram.

Study Protocol

Patients with severe obesity referred to the Centre for Obesity at St. Olavs Hospital, Trondheim, Norway, were offered the choice to attend a residential weight loss programme at Røros Rehabilitation Centre (RRC) (Norway). This intervention consists of a 'continuous care' weight loss programme with intermittent stays at the RRC. The groups from January 2005 to February 2007 had five stays at the RRC over a 2-year period as follows (programme A): a long initial stay of 8 weeks at RRC, 8 weeks at home, 4 weeks at RRC, 4-5 months at home, 2 weeks at RRC, 6 months at home, 2 weeks at RRC, 6 months at home and 2 weeks at RRC. Because of work and family commitments many participants complained of the duration of the first stay. For that reason, a new programme (programme B) was introduced from February 2007 onwards involving a shorter first stay at RRC: 2 instead of 8 weeks.

During the first visit at RRC, each patient had an individual consultation with a team of health professionals (dietician, physical activity (PA) therapist, psychologist and psychiatric nurse). Patients took part in structured PA supervised by a PA therapist (2 sessions of group PA + 1 individual/day) and in a nutrition education programme on how to estimate energy needs, energy intake from food, healthy eating, healthy cooking etc. Participants had 6 meals/day (4 main meals: breakfast, lunch, dinner and evening meal and 2 snacks). Some of the meals were provided by the kitchen, others were prepared by the participants in groups, with the help of the dietician and a chef. All food/meals provided were ad libitum and followed the following guidelines: i) Eat at least five servings of vegetables, fruits and berries every day; ii) eat whole-grain products every day; iii) choose low-fat dairy products as part of the daily diet; iv) eat fish for dinner 2 or 3 times a week; v) choose lean meats and low-fat meat products; vi) limit the amount of processed meat and red meat; vii) select edible oils, liquid margarine and soft margarine rather than hard margarine and butter; viii) choose foods low in salt and limit the consumption of salt in cooking and food; ix) avoid foods and drinks high in sugar (choose water instead). The same guidelines were used during the nutritional education programme, and participants were asked to follow them during the home stays. The cornerstone of both programmes consisted on dynamic group-based psychotherapy where each patient was in charge of their own treatment. Moreover, a great effort was put into translating new knowledge and practices acquired at RRC to the home environment and establishing long-term support at home.

Body weight was assessed at baseline and before and after each visit, and $\mathrm{VO}_{2}$ peak was measured at baseline and at the beginning of each visit at RRC. Before measurements of $\mathrm{VO}_{2}$ peak, participants were informed about the test and instructed to exercise to their maximum limit. To familiarise with treadmill 
Martins et al.: Longer Length of First Stay in Intermittent Residential Programmes Is Associated with Larger Weight Loss at 1 and 2 Years

Table 1. Baseline characteristics of the participants ${ }^{\mathrm{a}}$

\begin{tabular}{lll}
\hline & Programme A & Programme B \\
\hline Age, years & $41.2 \pm 10.0$ & $42.2 \pm 11.2$ \\
Male/female ratio & 0.56 & 0.51 \\
Weight, $\mathrm{kg}$ & $134 \pm 20^{* *}$ & $126 \pm 19^{* *}$ \\
$\mathrm{BMI}, \mathrm{kg} / \mathrm{m}^{2}$ & $44.9 \pm 5.6^{*}$ & $43.3 \pm 5.4^{*}$ \\
VO2 peak, $\mathrm{ml} / \mathrm{min}$ & $3,211 \pm 716$ & $3,319 \pm 832$ \\
V02 peak, $\mathrm{ml} / \mathrm{kg} / \mathrm{min}$ & $24.2 \pm 4.4^{* *}$ & $26.3 \pm 5.5^{* *}$ \\
\hline
\end{tabular}

${ }^{a}$ Values are mean \pm SD. Averages with the same symbol denote statistically significant differences between programme $\mathrm{A}$ and programme B: ${ }^{*} \mathrm{p}=0.05 ;{ }^{* *} \mathrm{p}<0.01$.

walking, the test started on a flat treadmill where participants learned to walk without grasping the handrails. After a warm-up period, a facemask was placed on the subject's face for metabolic measurements using Oxycon Delta (Jaeger, Hochberg, Germany). The $\mathrm{VO}_{2}$ peak test was performed using a ramp protocol where the speed was constant and the incline was increased with $2 \%$ every minute until $\mathrm{VO}_{2}$ peak was reached. The average of the three highest 10 -s measurements determined $\mathrm{VO}_{2}$ peak. Heart rate was continuously recorded using a Polar Sport Tester (Polar Electro OY, Kempele, Finland).

A flow diagram of the study can be seen in figure 1.

\section{Statistical Analyses}

Statistical analysis was carried out using SPSS 15.0 (SPSS Inc., Chicago, IL, USA). All variables were checked regarding their normal distribution using the Shapiro-Wilk test. Statistical significance was assumed at $\mathrm{p}<0.05$, unless otherwise stated.

Differences in baseline characteristics between the two groups were assessed using independent sample t-tests for continuous variables (BMI, weight, $\mathrm{VO}_{2}$ peak and age) and $\chi^{2}$ for categorical variables (male/female ratio). The same approach was used to look at differences between those who completed and those who withdrew from the study.

Because baseline weight was significantly higher in group A compared with group B and it was significantly correlated with weight loss at 1 year $(r=0.182, p>0.05, n=162)$ (but not at 2 years), we performed regression analysis to look at differences in weight between groups at different time points, using baseline weight as a covariate. Although baseline $\mathrm{VO}_{2}$ peak $(\mathrm{ml} / \mathrm{kg} / \mathrm{min})$ was significantly lower in programme A compared with B, there was no correlation with weight loss at either 1 or 2 years, and, for that reason, this variable was not included in the model. Changes in weight over time in each group were assessed by repeated measures ANOVA, using the Bonferroni test to adjust for multiple comparisons.

Changes in $\mathrm{VO}_{2}$ peak $(\mathrm{ml} / \mathrm{kg} / \mathrm{min})$ over time between programmes were assessed by a between/within subjects ANOVA, with group as between subjects variable and time as the within subjects variable. Differences in $\mathrm{VO}_{2}$ peak $(\mathrm{ml} / \mathrm{kg} / \mathrm{min})$ changes at 1 and 2 years in both groups were assessed by independent samples t-tests.

Apart from analysis of completers, we also performed two intention-to-treat analyses: 'last observation carried forward' and 'baseline values carried forward'.

\section{Results}

\section{Participants}

The study sample had a mean age of $42 \pm 11$ years and a BMI of $44.0 \pm 5.5 \mathrm{~kg} / \mathrm{m}^{2}$. Table 1 summarizes the baseline characteristics of the participants by treatment group. Age, $\mathrm{VO}_{2}$ peak $(\mathrm{ml} / \mathrm{min})$ and male/female ratio did not differ between groups, but baseline weight and BMI were significantly higher and $\mathrm{VO}_{2}$ peak $(\mathrm{ml} / \mathrm{kg} / \mathrm{min})$ significantly lower in group A compared with group B. 
Table 2. 1- and 2-year weight loss after two intermittent residential programmes ${ }^{a}$
Table 3. Percentage of participants who lost 5 or $10 \%$ of their initial body weight at 2 years within each treatment group ${ }^{\mathrm{a}}$
Martins et al.: Longer Length of First Stay in Intermittent Residential Programmes Is Associated with Larger Weight Loss at 1 and 2 Years

\begin{tabular}{lll}
\hline & Programme A & Programme B \\
\hline Analyse of completers & & \\
1-year weight loss, kg & $20.7 \pm 10.8$ & $13.5 \pm 8.1^{*}$ \\
1-year weight loss, \% & $15.7 \pm 8.1$ & $10.7 \pm 6.4^{*}$ \\
2-year weight loss, kg & $16.0 \pm 12.7$ & $7.9 \pm 11.2^{* *}$ \\
2-year weight loss, \% & $12.5 \pm 9.7$ & $6.1 \pm 8.9^{* *}$ \\
Last observation carried forward & & \\
1-year weight loss, kg & $20.1 \pm 10.9$ & $12.9 \pm 8.1^{* *}$ \\
2-year weight loss, kg & $15.1 \pm 12.5$ & $8.2 \pm 10.1^{* *}$ \\
Baseline carried forward & & \\
1-year weight loss, kg & $18.7 \pm 12.0$ & $12.3 \pm 8.6^{* *}$ \\
2-year weight loss, kg & $10.5 \pm 12.7$ & $5.2 \pm 9.9^{*}$ \\
\hline
\end{tabular}

${ }^{a}$ Values are mean \pm SD. Symbols denote statistically significant differences between programme A and programme B: ${ }^{*} p<0.01$; $* * \mathrm{p}<0.0001$

\begin{tabular}{lll}
\hline Percentage of weight loss & Programme A & Programme B \\
\hline $5 \%$ & $81 \%$ & $55 \%^{*}$ \\
$10 \%$ & $63 \%$ & $25 \%^{* *}$ \\
\hline
\end{tabular}

${ }^{a}$ Values are means. Symbols denote statistically significant differences between programme A and programme B: ${ }^{*} p<0,01$; ${ }^{* *} \mathrm{p}<0.0001$.

\section{Weight Loss at 1 and 2 Years}

There were no significant differences in baseline BMI, weight, $\mathrm{VO}_{2}$ peak (expressed in $\mathrm{ml} /$ $\min$ or $\mathrm{ml} / \mathrm{kg} / \mathrm{min}$ ) or age between those who completed the study and those who withdrew at 1 year. However, more men than women withdrew at 1 year $(17.7$ vs. $5.1 \%$; $<<0.05)$. There were also no significant differences in baseline BMI, weight, $\mathrm{VO}_{2}$ peak (expressed in $\mathrm{ml} / \mathrm{min}$ or $\mathrm{ml} / \mathrm{kg} / \mathrm{min}$ ) or gender ratio between those who completed the study and those who withdrew at 2 years, but completers were older compared with those who withdrew ( $43 \pm 10$ vs. $39 \pm 11$ years; $\mathrm{p}<0.05$ ).

Analysis of completers showed that participants in programme A lost significantly more weight, both at 1 and 2 years, compared with those in programme B (20.7 \pm 10.8 vs. $13.5 \pm$ $8.1 \mathrm{~kg}$ and $16.0 \pm 12.7$ vs. $7.9 \pm 11.2 \mathrm{~kg}$ respectively). A similar pattern was observed with intention-to-treat analysis (table 2).

The percentage of participants who lost at least 5 or $10 \%$ of their initial body weight at 2 years within each treatment programme can be seen in table 3 . Significantly more patients in programme $A$ were able to achieve $5 \%$ and $10 \%$ weight loss at 2 years, compared with programme B ( 81 vs. $55 \%$ ( $<<0.01)$ and 63 vs. $25 \%$ ( $p<0.0001)$ respectively).

\section{Changes in Weight throughout the 2-Year Intervention Period}

Changes in weight throughout the 2-year intervention period in patients who underwent programme A and B can be seen in figure 2. There was a significant effect of time on body weight in both treatment groups ( $\mathrm{p}<0.0001$ for both). 
Martins et al.: Longer Length of First Stay in Intermittent Residential Programmes Is

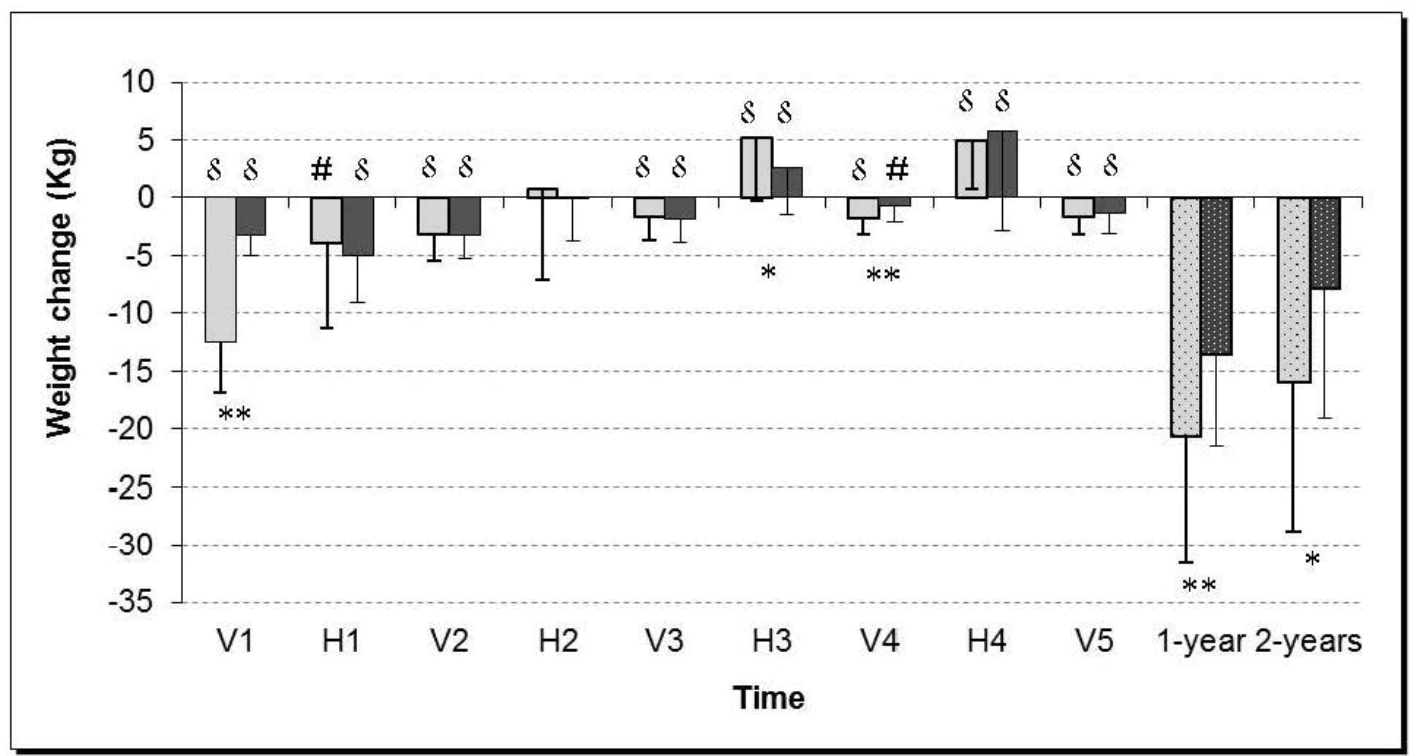

Fig. 2. Changes in body weight in two intermittent residential programmes over a 2-year period. Filled columns represent visits at RRC (V1 - visit 1, V2 - visit 2, V3 - visit 3, V4 - visit 4, V5 - visit 5) and home stays (H1 - first home stay, H2 - second home stay, H3 - third home stay, H4 - fourth home stay) and dotted columns cumulative weight loss at 1 and 2 years in programme A (lighter colour) and B (darker colour). Asterisks denote significant differences between programs $\left({ }^{*} p<0.01,{ }^{* *} p<0.0001\right)$ at different time points. Columns with symbols show significant changes in body weight overtime within group: $\$ p<0.0001, \# p<0.05$. Values are means \pm SD.

Fig. 3. Changes in $\mathrm{VO}_{2}$ peak (ml/ $\mathrm{kg} / \mathrm{min}$ ) in two intermittent residential programmes over a 2-year period. Lighter columns represent programme $A$ and darker columns programme B. V1-V5 represent visits atRRC. Values are means \pm SD. ANOVA revealed a significant effect of time ( $p<$ 0.0001 ) and a time $\times$ group interaction $(p<0.0001)$, but no main effect of group.

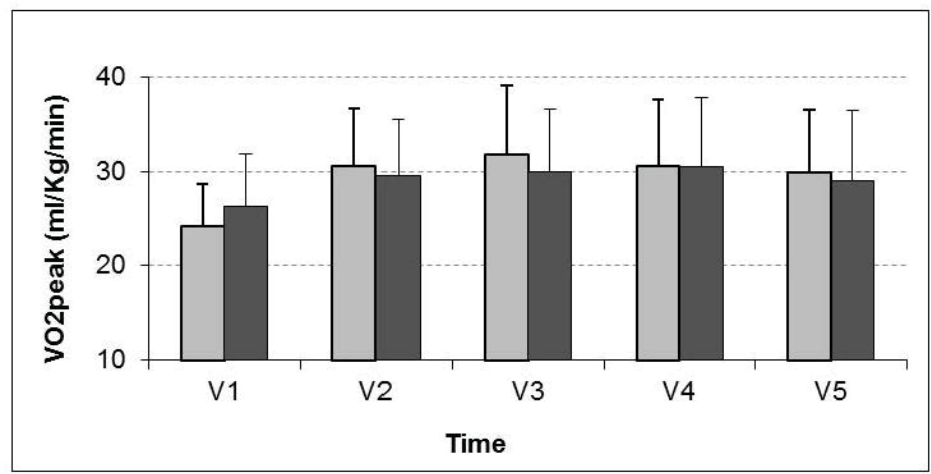

Participants lost significant amounts of weight at every stay at the RRC with both programmes, however, weight loss with programme A was significantly larger than with programme B both at the first (V1) and fourth (V4) visits: $-12.5 \pm 4.3 \mathrm{~kg}$ versus $-3.2 \pm 1.8 \mathrm{~kg}$ $(\mathrm{p}<0.0001)$ and $-1.8 \pm 1.4 \mathrm{~kg}$ versus $-0.7 \pm 1.4 \mathrm{~kg}(\mathrm{p}<0.0001)$ respectively. Participants in both programmes also lost significant and similar amounts of weight in the first home stay (H1: $-3.9 \pm 7.4 \mathrm{~kg}$ vs. $-5.0 \pm 4.1 \mathrm{~kg}, \mathrm{p}>0.05$ ), were able to maintain their weight during the second home stay (H2) and regained weight on both the third and fourth home stays (H3: $5.2 \pm 5.4 \mathrm{~kg}$ vs. $2.6 \pm 4.0 \mathrm{~kg}(\mathrm{p}<0.01)$ and $\mathrm{H} 4: 5.1 \pm 4.2 \mathrm{~kg}$ vs. $5.7 \pm 8.6 \mathrm{~kg}(\mathrm{p}>0.05)$ ). 
Martins et al.: Longer Length of First Stay in Intermittent Residential Programmes Is Associated with Larger Weight Loss at 1 and 2 Years

\section{Changes in Cardiovascular Fitness Overtime and at 1 and 2 Years}

Changes in $\mathrm{VO}_{2}$ peak $(\mathrm{ml} / \mathrm{kg} / \mathrm{min})$ over time in both programmes can be seen in figure 3 . ANOVA revealed a significant effect of time $(\mathrm{p}<0.0001)$ and a time $\times$ group interaction $(\mathrm{p}<$ $0.0001)$, but no main effect of group. There was a significant difference in $\mathrm{VO}_{2}$ peak $(\mathrm{ml} / \mathrm{kg} /$ $\mathrm{min}$ ) between groups at baseline, but no difference at any other time point.

There was a larger improvement in $\mathrm{VO}_{2}$ peak $(\mathrm{ml} / \mathrm{kg} / \mathrm{min})$ at both 1 and 2 years with programme A compared with programme B $(7.8 \mathrm{vs.} 3.6 \mathrm{ml} / \mathrm{kg} / \mathrm{min}(\mathrm{p}<0.0001)$ and $5.6 \mathrm{vs}$. $2.5 \mathrm{ml} / \mathrm{kg} / \mathrm{min}(\mathrm{p}<0.01)$ respectively).

\section{Discussion}

The main objective of this study was to compare weight loss and weight loss maintenance at 1 and 2 years and improvements in cardiovascular fitness over the same period in patients with severe obesity after two intermittent residential programmes differing in the length of their first stay. Programme A, with a first stay at RRC of 8 weeks, led to an initial weight loss that was, on average, four times higher than that observed with programme B, with a first stay of 2 weeks. So, the magnitude of weight loss was in fact directly proportional to the length of the stay. After that, participants of both programmes behaved in a very similar way, which is expected since the programmes were identical with the exception of the length of the first stay. Participants lost weight in their first home stay and second visit at the RRC, maintained their weight in the second home visit and lost weight during the third stay at RRC. After that, which corresponded to approximately 1 year, participants started to regain weight during their home stays and to loose minimal amounts of weight during their stays at the RRC. These findings may suggest that after the first year home stays need to be shortened and more frequent stays at the RRC are necessary in order to minimise weight regain. The better initial outcome of programme A was also maintained at both 1 and 2 years; those following programme A lost on average 34\% more weight at 1 year and $51 \%$ more weight at 2 years compared with those following programme B.

A larger initial weight loss has been consistently shown to be a good predictor of weight loss maintenance in the long term (2-3 years) [16-18]. This is in line with our findings showing that a larger initial weight loss achieved through a longer stay at a residential programme for morbid obesity is associated with better weight loss at 1 year and better weight loss maintenance at 2 years. Previous studies have shown that weight loss camps or in-patient programmes consisting of diet, physical activity and behavioural modification lead to very good short-term results with an average weight loss between 7 and $15 \%$ for periods between 3 and 21 weeks [11-13], which is consistent with our results. The problem is that, as soon as these programmes end and the patients are left without follow-up and support, weight regain starts to occur. Christiansan and colleagues [13] showed that, even though morbid obese patients can lose around $15 \%$ of their body weight during a 21 -week stay at a weight loss camp, participants regain more than half of the initial weight loss between 2 and 4 years. Similar results have been shown with behavioural or psychodynamic in-patient treatment: an average $5 \%$ weight loss can be observed after 7 weeks of in-patient treatment, but by 3 years, more than half of the weight had been regained [17]. By using intermittent residential programmes where patients receive continuing support, although weight regain cannot be avoided, it can be minimized. After 2 years, $81 \%$ of those participating in programme A and $55 \%$ of those participating in programme B maintained at least a $5 \%$ weight loss.

The improvements in cardiovascular fitness $\left(\mathrm{VO}_{2}\right.$ peak $\left.(\mathrm{ml} / \mathrm{kg} / \mathrm{min})\right)$ were also greater in programme A compared with programme B, at both 1 and 2 years. This suggests that the larger weight loss observed in programme A compared with programme $\mathrm{B}$, is likely to be at 
Martins et al.: Longer Length of First Stay in Intermittent Residential Programmes Is Associated with Larger Weight Loss at 1 and 2 Years

least partially explained by a larger increase in physical activity levels compared with those following programme B. Therefore, a longer initial stay seems to be more helpful in initiating and maintaining changes in physical activity in morbidly obese patients.

Retention rates were very good at 1 year (average 90\%); however, at 2 years they averaged only $65 \%$. Although low retention rates could have distorted our results, it is important to notice that retention rates were almost identical in both programmes and that there were no significant differences in baseline BMI, weight or cardiovascular fitness between those who completed and those who withdrew from the study both at 1 and 2 years. This probably explains why our intention-to-treat analysis, using both last observation carried forward and baseline carried forward, gave similar results to the analysis of completers, in terms of weight loss at 1 and 2 years.

In a recently published study, Mæhlum and colleagues [19] showed that 14 weeks of an in-patient treatment programme for morbidly obese patients focusing on physical activity, nutrition and behavioural intervention led to an average $12 \%$ weight reduction and that with additional 1 -week stays, 16 and 32 weeks afterwards, weight loss can be maintained at 1 year. These results are very similar to ours: weight reduction at 1 year of $11 \%$ (programme B) or $16 \%$ (programme A). More research is needed to ascertain the best design of intermittent residential programmes for morbid obesity, namely the length of the initial first stay and the frequency and duration of follow-up stays to minimise cost and maximise weight loss maintenance in the long term.

We need to acknowledge that the programmes described in this article are not a treatment offer available to all patients with morbid obesity in Norway and that only some health regions within the country offer part of this programme (1-3 sessions over a 1-year period) on a regular basis. Moreover, we need to recognise that the economic cost associated with these programmes is high (programme A: 18 weeks in-patient treatment over a 2-year period $\approx$ NOK 252,000 (EUR 34,000) (daily cost of $\approx$ NOK 2,000 (EUR 270); PROGRAM<ME B: 12 weeks in-patient treatment over a 2-year period $\approx$ NOK 170,000 (EUR 23,000)) and that in many other countries these programmes may not be economically feasible. Although we have not performed a complete cost analysis, it is important to mention that the cost of bariatric surgery (Roux-en-Y gastric bypass) in our hospital is $\approx$ NOK 100,000 (EUR 13,500), excluding pre- and post-operative evaluations and follow-ups. Overall, and despite the costs, this study reassures health professionals that clinical significant weight loss can be achieved and maintained over a 2-year period with conservative treatment.

In conclusion, intermittent residential programmes for morbid obesity, with a longer initial stay, seems to be better in inducing and maintaining a larger weight loss and improvements in cardiovascular fitness at both 1 and 2 years. However, family and work pressure need to be taken into account and for some in-patient long stays may not be feasible. A longer follow-up is also needed to clearly establish the sustainability of these programmes.

\section{Acknowledgements}

We would like to thank all the participants that took part in this study for their time and enthusiasm, Mrs. Sissel Salater for clinical assistance and the Central Norway Regional Health Authority (RHA) for funding.

\section{Disclosure Statement}

The authors declare that there is no conflict of interest that would prejudice the impartiality of this scientific work. 
Martins et al.: Longer Length of First Stay in Intermittent Residential Programmes Is Associated with Larger Weight Loss at 1 and 2 Years

\section{References}

1 World Health Organization: Obesity and Overweight. www who int/mediacentre/factsheets/fs311/en/.

$\longrightarrow 2$ Must A, Spadano J, Coakley EH, Field AE, Colditz G, Dietz WH: The disease burden associated with overweight and obesity. JAMA 1999;282:1523-1529.

-3 Calle EE, Thun MJ, Petrelli JM, Rodriguez C, Heath CW Jr: Body-mass index and mortality in a prospective cohort of U.S. adults. N Engl J Med 1999;341:1097-1105.

4 IOTF and EASO: Obesity in Europe - the Case for Action. www easoobesity org/temp/report72 pdf.

5 Wadden TA, Butryn ML, Wilson C: Lifestyle modification for the management of obesity. Gastroenterology 2007;132:2226-2238.

6 Sjostrom L, Lindroos AK, Peltonen M, Torgerson J, Bouchard C, Carlsson B, Dahlgren S, Larsson B, Narbro K, Sjostrom CD, Sullivan M, Wedel H, the Swedish Obese Subjects Study Scientific Group: Lifestyle, diabetes, and cardiovascular risk factors 10 years after bariatric surgery. N Engl J Med 2004;351:2683-2693.

7 Strømmen M, Kulseng B, Vedul-Kjelsås E, Johnsen H, Johnsen G, Mårvik R: Bariatric surgery or lifestyle intervention? An exploratory study of severely obese patients' motivation for two different treatments. Obes Res Clin Pract 2009;3:193-201.

8 Elder KA, Wolfe BM: Bariatric surgery: a review of procedures and outcomes. Gastroenterology 2007;132: 2253-2271.

- Blackburn G: Effect of degree of weight loss on health benefits. Obes Res 1995;3(suppl 2):211s-216s.

10 Knowler WC, Barrett-Connor E, Fowler SE, Hamman RF, Lachin JM, Walker EA, Nathan DM, Diabetes Prevention Programme Research Group: Reduction in the incidence of type 2 diabetes with lifestyle intervention or metformin. N Engl J Med 2002;346:393-403.

11 Shapiro JR, Stout AL, Musante GJ: 'Structure-size me:' weight and health changes in a four week residential program. Eat Behav 2006; 7:229-234.

-12 Maffiulettil NA, Agosti F, Marinone PG, Silvestri G, Lafortuna CL, Sartorio A: Changes in body composition, physical performance and cardiovascular risk factors after a 3-week integrated body weight reduction program and after 1-y follow-up in severely obese men and women. Eur J Clin Nutr 2005;59:685-694.

13 Christiansen T, Brunn JM, Madsen EL, Richelsen B: Weight loss maintenance in severely obese adults after an intensive lifestyle intervention: 2- to 4-year follow-up. Obesity 2007;15:413-420.

14 Sjostrom M, Karlsson AB, Kaati G, Yngve A, Green LW, Bygren LO: A four week residential program for primary health care patients to control obesity and related heart risk factors: effective application of principles of learning and lifestyle change. Eur J Clin Nutr 1999;53(suppl 2):S72-S77.

15 Martins C, Strømmen M, Stavne OA, Nossum R, Mårvik R, Kulseng B: Bariatric Surgery versus lifestyle interventions for morbid obesity - changes in body weight, risk factors and comorbidities at 1 year. Obes Surg 2011;21:841-849.

-16 Svetkey LP, Ard JD, Stevens VJ, Loria CM, Young DY, Hollis JF, Appel LJ, Brantley PJ, Kennedy BM, Kumanyika SK, Batch BC, Corsino L, Lien LF, Vollmer WM: Predictors of long-term weight loss in adults with modest initial weight loss, by sex and race. Obesity (Silver Spring). 2012;20:1820-1828.

17 Wiltink J, Dippel A, Szczepanski M, Thiede R, Alt C, Beutel ME: Long-term weight loss maintenance after inpatient psychotherapy of severely obese patients based on a randomized study: predictors and maintaining factors of health behavior. J Psychosom Res 2007;62:691-698.

18 Greenberg I, Stampfer MJ, Schwarzfuchs D, Shai I, DIRECT group: Adherence and success in long-term weight loss diets: the dietary intervention randomized controlled trial (DIRECT). J Am Coll Nutr 2009;28:159-168.

19 Mæhlum S, Danielsen KK, Heggebø LK, Schiøll J: The Hjelp24 NIMI Ringerike obesity clinic: an inpatient programme to address morbid obesity in adults. Br J Sports Med 2012;46:91-94. 